\title{
Effect of Borage on hipocampal TNF- $\alpha$ protein and gene in the Amyloid $\beta$-Peptide(25-35)-Induced of Alzheimer model in rat
}

\author{
Ehsan Barati ${ }^{1}$ Sara Soleimani Asl ${ }^{2}$,Seyed Ali Pourbakhsh ${ }^{1}$, \\ Mahmoud Jamshidian $^{1}$ and Siamak Shahidi ${ }^{2}$ \\ ${ }^{1}$ Department of Microbiology,Science and Research Branch, \\ Islamic Azad University,Tehran,Iran . \\ ${ }^{2}$ Department of Neurophysiology, School of Medicine, \\ Hamadan University of Medical Sciences, Hamadan 65178-3-8736, Iran.
}

http://dx.doi.org/10.13005/bbra/2000

(Received: 17 December 2015; accepted: 01 February 2016)

\begin{abstract}
Alzheimer's disease (AD) is a neurodegenerative disorder and most common form of dementia that leads to memory impairment. In the present study we have examined the investigating effect of Borago officinale on hipocampal TNF- $\alpha$ protein in the Beta Amyloid peptid induced of inflammation in the rat. Wistar male rats received intrahippocampal (IHP) injection of the $A \beta(25-35)$ and borage extract orally $(100 \mathrm{mg} /$ $\mathrm{kg}$ ).inflamation was confirmed by pathologist.in order to measure the expression of the TNF- $\alpha$ gene , RT- PCR method and for extraction of the TNF- $\alpha$ protein western bloting method was used. results showed that using Borage lead to reduce TNF- $\alpha$ gene and protein. This data suggests that borage could improve the reduction of inflammation factors such as TNF- $\alpha$ and borage consumption may lead to an improvement of ADinduced cognitive dysfunction.
\end{abstract}

Key words: TNF- $\alpha$, Alzheimer, RT-PCR,Western Blot,Amyloid $\beta$-Peptide

Alzheimer's disease (AD) and inflammation of brain immune system happen simutabously.Based on Walsh and et al 2012 investigations.increase of complement proteins , cytokines, microglia cells and astrocyts are observed(Walsh et al, 2012). These protein groups can do intermediation and set all aspects of natural and acquired immunes(choi and et al 2014). Some of these cytokines can lead to inflammation in the body. TNF- $\alpha$ can be probably considered as the most inflammatory cytokines. Based on Rinne and et al investigations, Monocyts and Macrophage are two important features lead to TNF- $\alpha$ producing cells(Rinne and et al,2003).

\footnotetext{
* To whom all correspondence should be addressed. E-mail: ehsanbarati@yahoo.com
}

In Alzheimer disease around the nerve cells setting Beta Amyloid can lead to microglia activity,free radical producing and inflammatory processing and hurt the healthy neurons (Sarter and et al , 2004)

In order to measure the effect of antiinflammatory Borage, a large number of studies were carried out by several investigators such as Kast and et al. They found that oil of Borage causes the reduction of inflammation because of the existence of GLA and increasing of the synthesis of Prostaglandin E and cAMP(Mattson and et al, 2004).

Cameron and et al studied the Herbal treatment of arthritis disease and emphasized that Borage reduces the rate of inflammatory cytokines because of the existence of GLA(Cameron and $e t$ $a l, 2006)$. 
Although a large number of investigations were carried out in Alzheimer disease, it seems that there is no sufficient studies in the current field. In the present study, effects of Borage in decreasing inflammation and decreasing of inflammatory factors such as TNF- $\alpha$ were studied. In order to examine these effects, peptid beta amyloid and Alzheimer model in rat were used.

\section{MATERIALSANDMETHODS}

The $A \beta(25-35)$ was purchased from sigma-Aldrich company (St Louis, MO, USA). Borage leaves were obtained in dried condition from Research Institute for Islamic and Complementary Medicine (Tehran, Iran). A $\beta$ 2535 was solubilized in sterile water at $1 \mu \mathrm{g} / \mu \mathrm{L}$ concentration and stored at $-20^{\circ} \mathrm{C}$ (Allen 2002).

\section{Animals}

28 250-300 gram weight male wistar rats were chosen for experimental procedure.all animals were housed in group and remained 21 degree centigrade along all the experimental procedure. Humidity of the house condition was 50\%. $12 \mathrm{hr}$ light/12 hr dark cycle was used for light housing condition.(Shankar and et al2008).

The rats randomly were classified in to the following groups: the control or intact group that was left undisrupted; the sham-operated group; the A $\beta 25-35$ model group which received single bilateral intrahippocampal (IHP) injections of A $325-35$;the borage-treated group that received borage extract (orally, $100 \mathrm{mg} / \mathrm{kg}$ ) following IHP injection of A $\beta 25-35$ for 14 days (Kast and et al 2001).

\section{Preparation of Borage Extract}

Dried borage leaves were cleaned carefully, then ground into coarse powder by electrically driven device. The powdered material was soaked into aqueous ethanol (80\%) for one week with occasional shaking. The extract was filtered through a Whatman filter paper and evaporated to dryness under reduced pressure at a maximum of $40^{\circ} \mathrm{C}$ using a rotary evaporator. Borago officinalis produced $10.9 \%$ dried extract. The extract was completely dissolved in purified water and kept at $4^{\circ} \mathrm{C}$ (La Ferla and et al 1995). Intrahippocampal Injection of A $\beta 25-35$

The animals were anesthetized with the ketamine $(100 \mathrm{mg} / \mathrm{kg})$ and xylazine $(10 \mathrm{mg} / \mathrm{kg})$ and were transferred to a stereotaxic apparatus (Stoelting, Wood Dale, IL, USA). The injection was made using a $10 \mu \mathrm{L}$ microsyringe (HamiltonReno, NV, USA). Relative to the bregma and with the stereotaxic arm at $0^{\circ}$, the coordinates for the toothed gyrus were posterior -3.6; lateral $\alpha 2.3$; and dorsal $3 \mathrm{~mm}$ (Conforti and et al 2008).

$\mathrm{A} \beta$ solution $(6 \mu \mathrm{L})$ was bilaterally injected into the area over $1 \mu \mathrm{L} / 2 \mathrm{~min}$. the cannula was left in place for 2 min after each injection to allow for spread. Sham operated rats received vehicle solution(10). The skin was then stitched and the animals were left to recover in a warm box before returning to their home cages. The injection place was checked by injection trypan blue instead of peptide in preliminary experiments (Figure 1).

\section{Histological Verification}

For verification of the injection place a light microscope (Olympus, Japan) was used, the trypan blue injected rats were perfused with $4 \%$ paraformaldehyde in $0.1 \mathrm{M}$ phosphate buffer $(\mathrm{p} \mathrm{H}$ $=7.3$ ) and the hippocampi were serially sectioned into $10 \mu \mathrm{m}$ coronal parts by a microtome (Leica Instruments, Germany). After deparaffinization and rehydration, sections were stained in $0.1 \%$ cresyl violet for 3 minutes. Finally, the parts were photographed with a digital camera (Olympus, DP 11, Japan) attached to a microscope (Olympus Provis, Ax70, Japan) and the stained pieces were qualitatively analyzed for the injection site(Klementiev and et al 2007).

\section{RT-PCR Experiment}

The day after the last treatment,the animals were eutha-nized by cervical dislocation. The brains were removed; hippocampi were immediately dissected out on ice, and then frozen in liquid nitrogen and kept at $-80^{\circ} \mathrm{C}$ until use.

Total mRNA was extracted from the frozen hippocam-pi by using phenol-chloroform method. Tissue samples were homogenized in 1000 il RNATM (Cinnagen, Teh-ran, Iran) then 200 ìl icecold chloroform was added. The homogenates were centrifuged (Eppendrof, Ham-burg, Germany) at $12000 \mathrm{~g}$ for $20 \mathrm{~min}$ in $4^{\circ} \mathrm{C}$. The RNA of the supernatant was precipitated with isopropanol, and washed with ethanol $75 \%$. The air-dried RNA pellet was dissolved in RNase free water. cDNA firststrand synthesis was performed using a cDNA synthesis Kit (Quiagen, Hilden, Germany). First strand cDNA was used as template for subsequent 
PCR with a PCR mas-ter kit (Cinnagen, Tehran, Iran), and primers (Cinnagen, Tehran-Iran) as follow: $\beta$ Actin Forward 5‘-GTG GGC CGCCCTAGG CAC CAG-3،

Reverse 5'- GGC CTT AGG GTT CAG AGG GG-3“ TNF- $\alpha$ Forward 5‘-AAC TTC GGG GTG ATT GGT CC -3 “

Reverse 5'-CTG AGT GTG AGG GTC TGG GC-3“

The PCR reactions included initial denaturation at $95^{\circ} \mathrm{C}$ for $3 \mathrm{~min}$, followed by 35 cycles with $95^{\circ} \mathrm{C}$ for $50 \mathrm{~s}, 58^{\circ} \mathrm{C}$ for $45 \mathrm{~s}$ and $72^{\circ} \mathrm{C}$ for $50 \mathrm{~s}$ for TNF- $\alpha$.

The reactions were terminated by $72{ }^{\circ} \mathrm{C}$ for $7 \mathrm{~min}$ of elongation period. The same annealing temperature was used for $\beta$-actin. PCR products were separated by electrophoresis in $1.5 \%$ agarose gel at $100 \mathrm{~V}$. Our semi-quantitative analysis were made using a digital imaging system (UVIdoc,Houston,Texas,USA).

\section{Western blot analysis}

Hippocampus tissue collected for Western blot analyses were snap frozen in liquid nitrogen and stored at $-70^{\circ} \mathrm{C}$ until use. Total protein was extracted by homogenization in RIPA buffer (150 mM NaCl, 50 mM Tris-HCl, pH7.5, 1\% Triton $\mathrm{X}, 0.5 \% \mathrm{Na}$ deoxycholate, $1 \mathrm{mM}$ PMSF) as described previously .

Protein concentration of homogenates was measured and 30 ìg resolved by $12 \%$ SDSPAGE and transferred to nitrocellulose membranes (MSI, Westboro, MA, USA). Membranes were blocked in 5\% non-fat milk for $1 \mathrm{~h}$ at room temperature and probed with polyclonal rabbit antimouse StAR antibody diluted 1:5000 in Trisbuffered saline/0.1\% Tween-20 (TBST). Following this membranes were incubated with biotinylated goat anti-rabbit IgG for $1 \mathrm{~h}$ at room temperature (diluted 1:10,000 in TBST). Membranes were then incubated with Avidin Biotin Enzyme Reagent for $1 \mathrm{~h}$ at room temperature and protein

signals detected by enhanced chemiluminescence (Supersignal West Pico ECL substrate, Pierce, Rockford, IL, USA) and quantitated by densitometry. A common tissue sample was included on each gel to allow for standardization of chemiluminescence levels and exposure times. Staining of each gel (post transfer) and membrane with Coomassie Brilliant Blue (Sigma Chemical Co.) assessed the accuracy of sample loading and the efficiency of protein transfer. This procedure was repeated for each animal/ experimental group.

\section{Statiscal analayses}

Data were presented as mean \pm S.E.M and analyzed by SPSS version 21 software. The data of the IL-1 Beta protein and gene were analyzed using two-way analysis of variance (ANOVA), Tukey multiple comparisons tests were used to analyze the significance of the differences between the groups, when appropriate value of $\mathrm{p}<0.05$ was considered significant ${ }^{11}$.

Briefly, the Homogenous test was used to prove the variance homogeneity amoung the experiment groups.

\section{RESULTS}

Histological analysis showed that injection of $A \beta$ was in their desired location, according to the atlas of Paxinos and Watson (Figure 1) (Conforti and et al 2008).

\section{The study of the expression of TNF- $\alpha$ gene}

The obtained results from RT- PCR show that TNF- $\alpha$ gene has a significant reduction amoung the intact groups in comparison with Beta amyloid and Borage $(\mathrm{p}<0.05$ for both groups of Beta amiloid), that show the increase for the expression of this gene amoung the Beta amyloid and Borage groups.

Priscriping the Borage caused a significant reduction in TNF- $\alpha$ gene after creating Alzheimer model.

The result obtained from the statistic analyzing TNF- $\alpha$ in attendance groups by ANOVA method showed that there is a significant difference amoung the experimenting groups .

The Tukey test was used because of the significient difference . the results of this test showed that a significant difference was not observed under the conditions of experiment amoug the Sham and Intact groups from the view point of TNF- $\alpha$. Also a significant difference was observed between the Sham and Intact group in comparison with Beta amyloid and Borage groups.

In this test , a significant difference was observed between the Beta amyloid and Borage groups from the view point of TNF- $\alpha$.

Briefly the Homogenous test was used to prove the variance homogeneity amoung the attendance groups that the result of this test was 
not significant amoung the attendance groups under the conditions of experiment,that it showed the variance homogeneity amoung the test groups. The study of the rate of the expression of protein in TNF- $\alpha$

Dansitometery, the nitro selolose membrane of the protein in Borage and Beta amyloid showed that the rate of this protein in Borage and Beta amyloid groups had a significant increasein comparison with intact and Sham groups. The priscription of the Borage after creating Alzheimer model caused a significant reduction of the rate of the expression of the TNF- $\alpha$ protein in comparison with the Beta amyloid group.
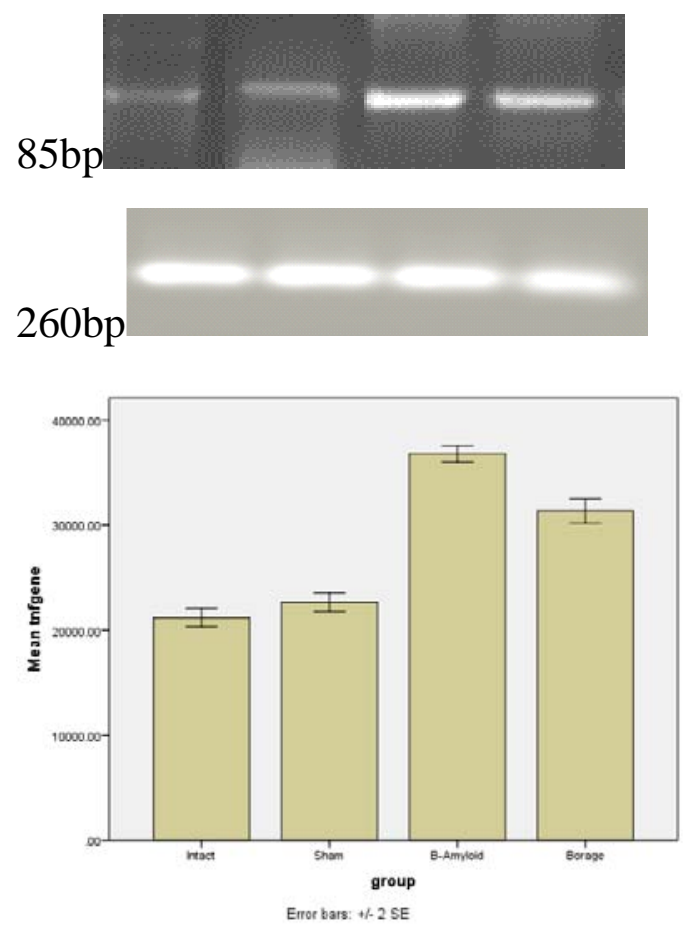

Fig. 1. RT-PCR analysis of the TNF- $\alpha$ expression in sham and treatment groups

\section{DISCUSSION}

The results obtained from the present study showed that the prescription of Beta amyloid leads to the increase of the expression of gene and protein TNF- $\alpha$ in hippocampus area. Also the prescription of Borage juice after creating Alzheimer model reduced the injected inflammation caused by Beta amyloid.

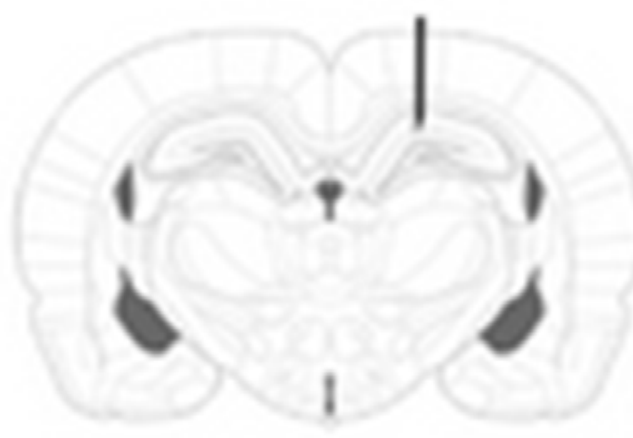

Fig. 1. Schematic photograph representing the microinjection site of Amyloid $\beta$ into the hippocampus (black arrow)
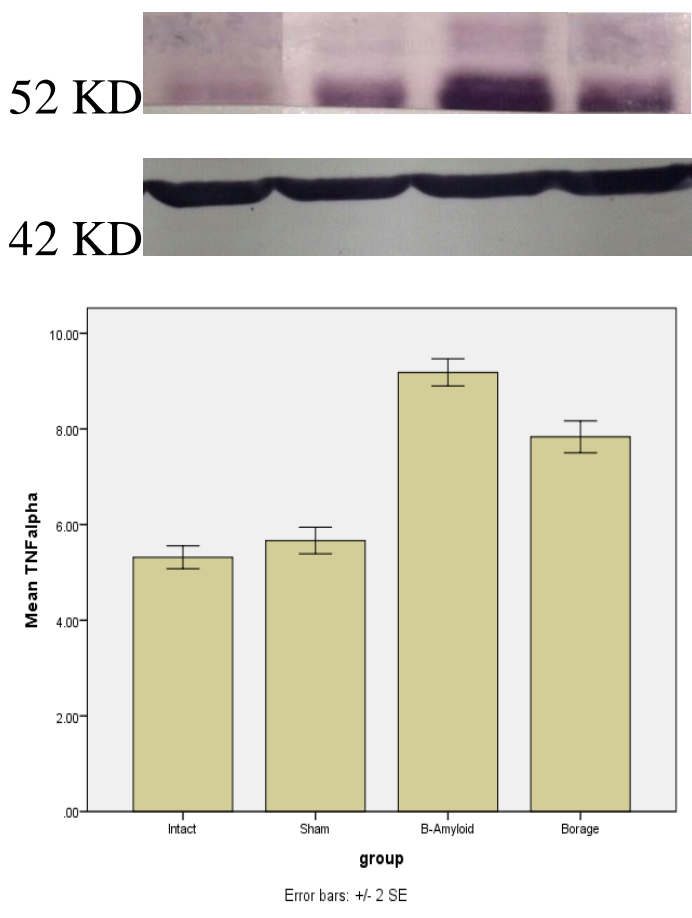

Fig. 2. Western Blot analysis of the TNF- $\alpha$ expression in sham and treatment groups

In present study the mutual injection in hippocampus Beta amyloid ${ }^{25-35}$ leads to creating inflammation and increasing inflammatory proteins . In agreement with our study Yamaguchi and et al . reported that prescription of Beta amyloid ${ }^{25-35}$ causes Alzheimer(Zussi and et al 2011).

The various experimental studies reported the role of rich feeding from anti-inflammations and anti-oxidants in recovery of neuro toxicity and 
recovery of the act of the brain(Cappai and et al 2008).

Great numbers of the medicinal plants were used in neurotic disease as anti-inflammation. Amoung these plants , the Borago Officinalis has a great importance because of having much Gama Linolenic Acid(GLA)(Yamaguchi and Kawashima 2001).

Gundgrade and et al, in a research that they did about Borago Officinale, got this result that Borage reduces the danger of catching diseases such as cancer, diabet and Alzheimer(Gundgrade and et al 2002).

In a research that Kapoor and et al did about the effect of GLA a natural anti-inflammation , got this result that GLA prevents producing of the IL-1 Beta and its releasing by monocyte and in this way causes the reduction of inflammation . also GLA causes secrection of prostaglandin $E$ and this factor finally causes the reduction of producing TNF- $\alpha$ and in this way the inflammation finally reduces(Kappor and et al 1999).

Sadiya and et al in a research that they did about Borago Officinale declared that this plant has more than 20\% GLA and traditionally it is used in the treatment of Romatoid and has positive and useful effect on the brain(Sadiya and et al 2000).

Kast and et al in a research that they did about the anti-inflammation effect of the oil of Borago Officinale got this result that it causes the reduction of inflammation because of the existence of GLA and increasing of the synthesis of prostaglandin E and CAMP(Kast and et al 1998).

In a research that Cameron and et al did about the Herbal treatment of arthritis romatoid disease, emphasized that Borago Officinale reduces the rate of inflammatory cytokins because of the existence of GLA(Cameron and et al 2006).

The result of this study showed that using the Borage juice after the injection of Beta amyloid lead to the reduction of inflammation . in the present study after analyzing the results of the experiment by SPSS software version 21 , it was confirmed that the surgical operation has had no effect on the results of the experiment. By the injection of Beta amyloid in hippocampus , the rate of the gene expression and protein TNF- \pm in the Borage and Beta amyloid group get a significant increase in comparison with the Sham and Intact groups which this is a confirmation on the created inflammation after the injection of Beta amyloid. After the consumption of the alcolic juice of Borago Officinale the rate of the gene expression and hippocampic TNF- \pm protein get a significant reduction in comparison with Beta amyloid group which it is the confirmation in the hypothesis of the present study which declars that the consumption of Borago Officinale casues the reduction of the created inflammatory factors in the Alzheimer model which is created by peptid Beta amyloid in hippocampus .

Generally it seems that the Borago Officinale reduces the effect of inflammatory proteins and in this way it reduces the effects of inflammatory Beta amyloid.

Brifly , the results of the present study declare that the prescription of the Borago Officinale reduces the injected inflammation by Beta amyloid(25-35) and therefore it may be useful in the treatment of some disease as Alzheimer.

\section{REFERENCES}

1. D. Allan Butterfield, A. Castegna, C. M. Lauderback, and J. Drake, "Evidence that amyloid beta-peptide-induced lipid peroxidation and its sequelae in Alzheimer's disease brain contribute to neuronal death," Neurobiology of Aging, 2002; 23(5): 655-664 .

2. R. Cappai and K. J. Barnham, "Delineating the mechanism of Alzheimer's disease A beta peptide neurotoxicity," Neurochemical Research, 2008; 33(3): 526-532.

3. C.Cameron, A. Deshpande, E. Mina, C. Glabe, and J. Busciglio, "Different conformations of amyloid 2 induce neurotoxicity by distinct mechanisms in human cortical neurons,” Journal of Neuroscience, 2006; 26(22): 6011-6018.

4. S. S. Choi, S. R. Lee, S. U. Kim, and H. J. Lee, "Alzheimer's disease and stem cell therapy," Experimental Neurobiology, 2014; 23(1): 4552.

5. F. Conforti, S. Sosa, M. Marrelli et al., "In vivo anti-inflammatory and in vitro antioxidant activities of Mediterranean dietary plants," Journal of Ethnopharmacology, 2008; 116(1): 144-151.

6. S.Gundgrade Q. L. Peng, A. R. Buz’Zard, and B. H. S. Lau, "Pycnogenol protects neurons from amyloid-2 peptide-induced apoptosis," Molecular Brain Research, 2002; 104(1-2): 5565.

7. D. F. Horrobin, C. Stewart, H. Carmichael, and 
G. C. Jamal, "Use of gamma-linolenic acid and related compounds for the manufacture of a medicament for the treatment of complications of diabetes mellitus," European Patent 1993; 218,460.

8. D.Kappor S. Foster and V. E. Tyler, Tyler's Honest Herbal: A Sensible Guide to the Use of Herbs and Related Remedies, Routledge, New York, NY, USA, 1999.

9. H.Kast, M. M. Engler and M. B. Engler, "Dietary borage oil alters plasma hepatic and vascular tissue fatty acid composition in spontaneously hypertensive rats," Prostaglandins, Leukotrienes and Essential Fatty Acids, 1998; 59(1): 11-15.

10. B. Klementiev, T. Novikova, V. Novitskaya et al., "A neural cell adhesion molecule-derived peptide reduces neuropathological signs and cognitive impairment induced by A $\beta 25$-35," Neuroscience, 2007; 145(1): 209-224.

11. F. M. LaFerla, B. T. Tinkle, C. J. Bieberich, C. C. Haudenschild, and G. Jay, “The Alzheimer's $\mathrm{A}^{2}$ peptide induces neurodegeneration and apoptotic cell death in transgenic mice," Nature Genetics, 1995; 9(1): 21-30.

12. Y. Matsuoka, M. Picciano, J. la Francois, and K. Duff, "Fibrillar $\beta$-amyloid evokes oxidative damage in a transgenic mouse model of Alzheimer's disease," Neuroscience, 2001; 104(3): 609-613.

13. M. P. Mattson, S. Maudsley, and B. Martin, “A neural signaling triumvirate that influences ageing and age-related disease: insulin/IGF-1, BDNF and serotonin,” Ageing Research Reviews, 2004; 3(4): 445-464.

14. J. O. Rinne, V. Kaasinen, T. Järvenpää et al., "Brain acetylcholinesterase activity in mild cognitive impairment and early Alzheimer's disease," Journal of Neurology Neurosurgery and Psychiatry, 2003; 74(1): 113-115.

15. J.Sadiya L. S. Harbige, L. Layward, M. M. Morris-Downes, D. C. Dumonde, and S. Amor, "The protective effects of omega- 6 fatty acids in experimental autoimmune encephalomyelitis (EAE) in relation to transforming growth factorbeta 1 (TGF- $\beta 1$ ) up-regulation and increased prostaglandin E2 (PGE2) production,” Clinical and Experimental Immunology, 2000; 122(3): 445-452.

16. M. Sarter and J. P. Bruno, "Developmental origins of the age-related decline in cortical cholinergic function and associated cognitive abilities,” Neurobiology of Aging, 2004; 25(9): 1127-1139.

17. G. M. Shankar, S. Li, T. H. Mehta et al., "Amyloid- $\beta$ protein dimers isolated directly from Alzheimer's brains impair synaptic plasticity and memory," Nature Medicine, 2008; 14(8): 837-842.

18. D. M. Walsh and D. B. Teplow, "Alzheimer's disease and the amyloid $\beta$-protein," Progress in Molecular Biology and Translational Science, 2012; 107: 101-124.

19. Y. Yamaguchi and S. Kawashima, "Effects of amyloid- $\beta$-(25-35) on passive avoidance, radialarm maze learning and choline acetyltransferase activity in the rat," European Journal of Pharmacology, 2001; 412(3): 265-272.

20. C. Zussy, A. Brureau, B. Delair et al., "Timecourse and regional analyses of the physiopathological changes induced after cerebral injection of an amyloid $\beta$ fragment in rats,” The American Journal of Pathology, 2011; 179(1): 315-334. 